CLINICAL ETHICS

\title{
The complexity of nurses' attitudes toward euthanasia: a review of the literature
}

\author{
M Berghs, B Dierckx de Casterlé, C Gastmans
}

J Med Ethics 2005;31:441-446. doi: 10.1136/ime.2004.009092

In this literature review, a picture is given of the complexity of nursing attitudes toward euthanasia. The myriad of data found in empirical literature is mostly framed within a polarised debate and inconclusive about the complex reality behind attitudes toward euthanasia. Yet, a further examination of the content as well as the context of attitudes is more revealing. The arguments for euthanasia have to do with quality of life and respect for autonomy. Arguments against euthanasia have to do with nonmaleficence, sanctity of life, and the notion of the slippery slope. When the context of attitudes is examined a number of positive correlates for euthanasia such as age, nursing specialty, and religion appear. In a further analysis of nurses' comments on euthanasia, it is revealed that part of the complexity of nursing attitudes toward euthanasia arises because of the needs of nurses at the levels of clinical practice, communication, emotions, decision making, and ethics.

See end of article for authors' affiliations

Correspondence to: Professor C Gastmans, Faculty of Medicine, Centre for Biomedical Ethics and Law, Catholic University of Leuven, Leuven, Belgium; chris.gastmans@med. kuleuven.ac.be

Accepted for publication 11 October 2004
A dvances in medicine have led to significant progress in prolonging life. At the same time this progress has brought to the fore issues of quality of life, and heightened debates with respect to euthanasia. In Belgium and The Netherlands, laws have been passed allowing euthanasia under certain carefully delineated circumstances. In the Belgian euthanasia act, euthanasia is defined as the administration of lethal drugs at the explicit request of the patient with the explicit intention of shortening the patient's life. ${ }^{1}$

The debate about euthanasia continues worldwide, with nurses' attitudes becoming increasingly more important. ${ }^{2}$ The Belgian euthanasia act (Euthanasia Act, ${ }^{1}$ art $3 \$ 24^{\circ}$ ) stipulates that if there is a nursing team that has regular contact with a patient who requests euthanasia, the physician has to discuss the request of the patient with the nursing team. This is consistent with findings by Van der Heide et $a l^{4}$ that Belgium, out of six countries that were studied in Europe, had the highest rate (57\%) of nursing staff consultation by a physician, with respect to end of life decisions, indicating the central position of the nurse.

Even though empirical studies show that nurses, internationally, are involved in euthanasia, ${ }^{5}$ little is known about the clinical/ ethical reality behind nurses' attitudes toward euthanasia. This article undertakes a thorough analysis of the data in empirical literature concerning nurses' attitudes toward euthanasia. Emphasis is laid on the complexity within the content of nurses' attitudes and on the contextual complexity nurses are confronted within the formation of their attitudes.

\section{METHOD}

Using the Pubmed and Cinahl databases, scholarly publications published between 1966 and 2003 were located, using a combination of the following keywords: "euthanasia"; "nurse"; "nursing"; "attitudes"; "perspectives"; "opinions", and "characteristics". The literature selection took place on the basis of three predetermined inclusion criteria: 1) definition of euthanasia as the administration of lethal drugs with the explicit intention of shortening the patient's life at the patient's explicit request; 2) focus was on the attitudes of nurses toward euthanasia, and 3) English, French, or Dutch language publications.

At first sight, there appears to be a great deal of literature on the attitudes of nurses toward euthanasia, but after a thorough analysis of the content of these articles, the number of usable publications was reduced. In a large number of publications it is unclear what is meant by euthanasia. ${ }^{67}$ When clear definitions were given, the definition used did not always comply with the definition of euthanasia used in this review. ${ }^{8}$ Other studies dealt with extremely broad definitions of euthanasia that also fell outside our inclusion criteria. Asch et al-for example, ${ }^{10}$ dealt with both "active euthanasia and assisted suicide" and "withholding and withdrawing life sustaining treatments".

On the basis of the three inclusion criteria thirty studies were selected. The thirty studies comprised eighteen quantitative studies, ${ }^{11-29}$ nine qualitative studies, ${ }^{30-37}$ two literature reviews, ${ }^{23}$ and one anthropological account of euthanasia practice. ${ }^{38}$ The studies were set in the USA, $^{2}{ }^{15} 192327-2932$ Australia, ${ }^{11} 121618202533$ Japan, ${ }^{1326}$ Finland, ${ }^{24}{ }^{31}$ The Netherlands, ${ }^{36}{ }^{38}$ Canada, ${ }^{34}{ }^{37}$ Belgium, ${ }^{36}$ Switzerland, ${ }^{14}$ Israel, ${ }^{22}$ and Hungary. ${ }^{17}$ In addition, one study was set at an international midwifery conference ${ }^{21}$ and one was a cross cultural study. ${ }^{30}$ During the time that these studies were conducted, euthanasia was not legal in any of these countries. At the time when the Dutch studies were carried out, euthanasia was not legal in The Netherlands, however, it was not a punishable offence if the due care requirements were complied with. 
The method of analysis used in this paper consisted of a careful and thorough reading of all of the articles used. In the first stage, we examined only the differing data that were given when researching the attitudes of nurses toward euthanasia in quantitative studies. In the second stage, we examined the differing ethical arguments that justified the data in quantitative studies and then looked at ethical arguments behind opinion formation in qualitative studies. In the third phase we looked at the factors that influenced opinion formation in both quantitative and qualitative studies. In the last stage, we looked at the content of comments that nurses gave at the end of quantitative questionnaires and in qualitative interviews, and identified different "needs" of nurses that recurred frequently. The method of analysis was under continuous critical evaluation of a nursing academic researcher and two experts in nursing ethics research.

\section{NURSING ATTITUDES TOWARD EUTHANASIA}

When Verpoort et al ${ }^{3}$ examined quantitative studies that had replicated the questionnaires used by either Kuhse and Singer ${ }^{20}$ or Young et al ${ }^{28}$ which thus could be compared, they found a wide range of percentages covering nursing attitudes in favour of the legalisation of euthanasia. These percentages ranged from $14 \%{ }^{13}{ }^{26}$ to $78 \% .^{20}$ Other quantitative studies not using the Kuhse and Singer ${ }^{20}$ or the Young et a ${ }^{28}$ questionnaires, but asking the same question about the attitudes of nurses toward legalisation of euthanasia further corroborated such findings of variable percentages found in positive attitudes toward legalisation of euthanasia: these ranged from $23 \%,{ }^{29} 44 \%,{ }^{19} 50 \%,{ }^{11} 60 \%,{ }^{25}$ to $61 \% .{ }^{16}$

Verpoort et $\mathrm{al}^{3}$ found this variation in percentages from low to high was also illustrated when nurses were asked if euthanasia could be ethically justified: the range was from $21 \%{ }^{17}$ to $70 \%{ }^{21}$ Only in certain circumstances, such as in the case of terminal illness, was an ethical justification for euthanasia felt to be justified.

The myriad of differing percentages given when investigating attitudes of nurses toward euthanasia is indicative of the difficulty of the task of trying to give a nuanced picture of a complex reality. Many questions remain unsolved: What are the arguments nurses use to justify their attitudes? Are nurses' attitudes influenced by contextual factors? To clarify the reality behind such empirical data, a further examination was undertaken into the ethical content that nurses describe to explain their positions toward euthanasia.

\section{ARGUMENTS FOR OR AGAINST EUTHANASIA Ethical principles in practice}

Nurses indicate that when forming their arguments for or against euthanasia major ethical principles guide their thoughts. The literature review by Verpoort et al showed that the most important principles in arguments for euthanasia were quality of life and respect for autonomy. These principles were also indicated in other studies as being important in arguing for euthanasia. ${ }^{14} 192425302936$ The most important principles in arguments against euthanasia were found to be non-maleficence, ${ }^{33}$ sanctity of life, ${ }^{31} 3237$ and those to do with the idea of the slippery slope. ${ }^{32} 3337$

While it is true that major ethical principles can be identified in the way nurses form their arguments, they are not always used in the same way-that is, to mean the same thing. The principle of respect for autonomy-for example, was described as: the right of the patient to decide; ${ }^{20}$ the patient's own request; ${ }^{31}$ patient autonomy, ${ }^{19}$ and self determination. ${ }^{37}$ Moreover, "slippery slope" arguments were indicated by remarks such as: the need for better safeguards; ${ }^{11}$ potential abuse; $;^{19} 29^{31-33} 37$ the history of the
Nazi regime's euthanasia programmes, ${ }^{14}$ and economic considerations. ${ }^{32}$

There seems to be a gap between philosophical theorising and what nurses actually experience in clinical settings. ${ }^{11}$ While researchers identified nurses as all implicitly or explicitly using ethical principles to guide their decisions, nurses claimed not to know how abstract principles could be of help in clinical practice. Some explained that attitudes toward euthanasia involved "shades of grey"33 and this was often not reflected in the ethical polarisation of the debate. ${ }^{12}$

\section{Qualifications in agreement or disagreement}

Arguments for or against euthanasia distinguished between agreement at an individual and professional level. When there was no agreement at the individual level, nurses argued one had to respect a nurse's conscience, ${ }^{32}$ and this should not have to translate into actual involvement in euthanasia. When there was positive agreement that translated into positive involvement in the euthanasia process at the professional level, it was with some qualifications ${ }^{25}$ : onlyfor example, after good palliative care had been instituted, ${ }^{11}$ with clearly defined criteria, ${ }^{19}{ }^{31}$ or after euthanasia had been legalised..$^{18} 3037$

Nurses indicated that despite being against euthanasia, they would be willing to be involved in caring for patients who requested euthanasia. Cartwright et al ${ }^{16}$ found that despite the fact that $29 \%$ of Australian critical care nurses did not agree with euthanasia, they would stay with the patients who had requested euthanasia and give support. This indicates an ability in nurses to set aside their personal beliefs in order to provide optimal care for their patients. ${ }^{16} 222837$

While many nurses felt at a loss to explain their attitudes ethically and indicated how complex each individual situation was, they viewed their patients' ethical beliefs and legal rights as guides to structuring their own behavior and attitudes..$^{25} 33^{36}$ This does not mean that nurses follow their patients' ethical beliefs without qualification: while-for example, nurses indicated patients had a right to be autonomous decision makers, they also qualified that statement by pointing to the complexities of decision making. Among these complexities they named: the rights of the family, and the rights of the physician and the nurse, as well as other factors such as pain management, prognosis etc. This indicates a complex process of reflection in weighing multiple principles and factors. ${ }^{33} 37$

When confronted with an actual clinical setting where perhaps they had to administer the lethal drug, support would often dramatically fall, as in the case reported by Musgrave \& Soudry, ${ }^{21}$ where initially $70 \%$ of nurse/midwives agreed with euthanasia, $64 \%$ would stay with the patient, but only $36 \%$ would be willing to administer the lethal drug. These results were corroborated by findings which showed that many American and Israeli nurses refused to take the responsibility of administering the lethal drug to the patient. ${ }^{19} 2228$

\section{CONTEXTUAL FACTORS \\ Age}

It was found that younger nurses tended to be more accepting of euthanasia than older nurses. ${ }^{3} 182024$ Stevens and Hassan ${ }^{25}$ indicated that those nurses who were more likely to receive requests from patients for euthanasia were younger nurses, and that they were more likely adopt more positive attitudes toward euthanasia but they did not, however, always have close relationships with patients. Involvement in the euthanasia process requires an emotional maturity and responsibility that younger nurses are not always ready or willing to shoulder. ${ }^{33}$ 


\section{Nursing specialty}

Brown et $a l^{15}$ found that nurses most in favour of legalising euthanasia were floaters ${ }^{i}(52 \%)$, and nurses least in favour were the operating room/emergency room nurses $(22 \%)$ and the obstetrics and gynaecology nurses (26\%). Nurses, who had everyday contact and experience with the terminally ill, were the most against euthanasia. This correlation corresponds to Verpoort et al' $^{3}$ findings that oncology nurses are less in favour of legalising euthanasia than non-oncology nurses. It is also in line with Verpoort et al's findings that palliative care nurses were the only subgroup of nurses without a clear majority in favour of euthanasia. Bittel et al ${ }^{14}$ found that $29 \%$ of Swiss palliative care nurses and other palliative care professionals would offer euthanasia if this were allowed by law. Yet more than two thirds of both groups would refuse a patient's request for euthanasia even if it were legal. A Hungarian study ${ }^{17}$ indicated that nurses who had everyday contact with dying patients were more "conservative" than medical or social science students. These findings of a correlation between palliative care and a lower support for euthanasia are corroborated neither by Kuhse and Singer, ${ }^{20}$ nor by Kuupelomäki. ${ }^{31}$ Verpoort et al' ${ }^{36}$ findings showed that while the majority of Belgian palliative care nurses expressed negative attitudes toward euthanasia, they were not a priori for or against euthanasia. Overall, their attitudes tended to mirror the dynamics of clinical practice and could change depending on the situation of each individual patient.

\section{Religion}

A positive correlation for religious affiliation was found by Verpoort et $a l^{3}$ in a significant number of studies investigating nurses' attitudes against euthanasia. This connection between religion and nurse attitudes against euthanasia was also found in other studies. ${ }^{14} 2430$ Catholics were more likely to be against euthanasia than members of other religious groups. ${ }^{16} 20$ In their study of Belgian palliative nurses, Verpoort et $a l^{36}$ found, furthermore, that religious attitudes toward euthanasia are dynamic. If nurses were religious and found euthanasia problematic, they would not necessarily reject it as a possibility for patients, nor would they refuse to care for a patient who made this choice. This further corroborates findings that nurses are willing to set aside their beliefs in the interests of the patient. ${ }^{16222837}$

The correlates in age, nursing specialty, and religion shed light on the contextual factors that have an important role to play in the formation of arguments for or against euthanasia. Yet, such correlates tend to give a static picture and do not portray the process of how they are involved in the formation of attitudes.

\section{ANALYSIS OF NURSES' COMMENTS ON EUTHANASIA}

A further analysis of nurses' comments made in qualitative interviews or written at the end of quantitative questionnaires when invited, was undertaken. Comments made by nurses in all the studies were generally exploratory in nature, suggesting that nurses wanted to say something more about euthanasia, something that perhaps was not being addressed. It was revealed that part of the complexity of nurses' attitudes toward euthanasia arose out of the needs they said they had in terms of clinical practice, emotions, decision making, and ethics.

'Floaters are nurses who "float" or spend only a day or two on a specific service, or in administrative duties, and have less contact with terminally ill patients.

\section{Continuing education in palliative care}

Many of the nurses stressed the need for greater knowledge of palliative care, with some nurses believing that increased palliative care would eventually make euthanasia unnecessary. ${ }^{20} 29313237$ Nurses pointed out that it was easier to provide proper care for dying patients in palliative care settings than in hospital settings. ${ }^{33}$ Yet, even in palliative care settings, if palliative measures had been exhausted, nurses felt euthanasia could be a "final option". 202536

There was a call for more understanding of management of symptoms, ${ }^{11}$ and questions about whether administering large doses of narcotics did not hasten death. ${ }^{29}$ Many nurses indicated they felt uncomfortable with the ambiguity of such practices..$^{20} 32336$ Nurses indicated confusion about the role of morphine, with nurses unclear whether increasing morphine was not actively assisting in dying. ${ }^{11}{ }^{38}$ There was also a significant lack of clarity about whether, if nurses gave palliative sedation at the patient's request, they were not in fact thus actively involved in a patient's death. ${ }^{11}$

\section{Continuing education in communicative skills}

Nurses repeatedly called for better professional communication about end of life issues between nurses and physicians, and between professionals and patients. They often felt there was not enough time to provide optimal care, and indicated that they needed to be able to respond better to the existential crises of patients. ${ }^{11}{ }^{12}{ }^{36}$ Communication about euthanasia was often avoided, reduced to a business like character, or misunderstood completely. ${ }^{38}$ Nurses remarked that patients had a need to be helped to communicate on issues important to them as death approached. ${ }^{12} 32$

\section{Situating the emotions}

Matzo and Schwarz ${ }^{32}$ found that $20 \%$ of written comments by nurses at the end of their survey expressed emotions toward euthanasia. Nurses indicated that they did not understand how emotions could lie at the basis of ethical principles, aid them, or be viewed as positive experiences.

This was reflected in the way nurses felt more capable about the physical aspects of care, compared to the psychosocial aspects of care. ${ }^{29}$ At the same time, the psychosocial aspects of care of not only patients and families but also of nurses themselves, was indicated as crucial by nurses. ${ }^{35}$ Yet, just as physicians have great difficulties dealing with emotions of loss, failure, and fear with respect to patients who request euthanasia, so do nurses. ${ }^{16}$ Nurses, like doctors, also had to come to terms with their own attitudes and fears toward death. ${ }^{16}{ }^{28}$

Van der Brug et $a l^{35}$ reported that nurses involved in the euthanasia process indicated that while one had to focus on the care of the patient, one also had to mentally prepare oneself. Despite feelings of compassion for the patient, nurses said they also had feelings of guilt, anger, fear, and involvement in an "unnatural event". They all indicated a strong belief in the need to share what they had experienced-after the patient had died-with both the physician and nursing team. ${ }^{38}$

\section{Decision making}

Nurses realised the complexities of decision making. ${ }^{11}$ They noted the importance of the physician's role and the heavy burden of decision making. ${ }^{20}$ Some nurses indicated that they would never want to make that decision, nor shoulder such a responsibility. ${ }^{20}{ }^{32}{ }^{36}$ Nurses also said they saw their position as vulnerable and that they felt their opinions were overlooked..$^{1636}$

In the euthanasia process it is important that all involved reach a consensus, for it is difficult to begin the mourning process if one is not able to support a patient's decision. ${ }^{3638}$ Nurses-for example, indicated that if a patient's loved ones 
were not supportive of the decision, euthanasia could not occur, for the next of kin had to be able to continue with their lives. $^{36}$

It was clear that nurses once the euthanasia decision had been taken, "lived" that decision more intimately than the physician. While the patient had brief contact with the physician, nurses felt that they had to engage in the terminal illness and helplessness of both patients and families, on a daily basis. ${ }^{15}$

\section{Ethical guidelines, professionalism, and policy making}

Nurses' comments indicated tensions between the acceptance of euthanasia and the negative effect it could have on the trusting relationship between care givers and patients, as well as society. ${ }^{16} 2326$ 29-31 Likewise, studies also indicated the enormous fears of dying within society with regard to inadequate pain management, loneliness, and lack of control. $^{24}$ The interplay of these different fears led nurses to call for truer reflection on values held about euthanasia and attitudes toward it. ${ }^{23} 36$ As part of such a reflection, nurses argued, there should be a clarification of each institution's policy on euthanasia. ${ }^{23}$

Nurses who were in favour of euthanasia expressed support for legal policies and guidelines. ${ }^{1636}{ }^{37}$ Dutch nurses who were working in a care setting where guidelines were already in place, however, indicated that euthanasia was dealt with in a technical, business like, and unnatural way because of fears of not following the guidelines correctly. ${ }^{35} 38$ Furthermore, what the precise role of nurses was, and what procedures and practices they could engage in during the euthanasia process, was not clearly defined in the guidelines, and this added to nurses' fears of engaging in an illegal activity. ${ }^{35}$

The call for more reflection on the nursing profession's position toward euthanasia arises from the fact that the arguments found in ethical codes are not strongly supported by nurses. ${ }^{19}$ This suggests that nurses may be more concerned with factors that influence the wellbeing of a patient rather than with their professional identity. Despite the fact that nurses said they did not know how the ethical principles in their codes were of value in a clinical setting, nurses who expressed arguments for or against euthanasia, implicitly identified with ethical principles that were part of their professional identity or ethical codes. ${ }^{34}$ Asai et al ${ }^{13}$ point out, however, that whatever nurses' attitudes are toward euthanasia, whether for or against, it is a fact that nursing as a profession would never allow nurses to practise euthanasia.

\section{DISCUSSION AND CONCLUSION Methodological considerations}

When engaging in a literature review, at a time when euthanasia functions in an illegal sphere in the countries studied, there are several constraints regarding methodology and gathering empirical evidence. Likewise, caution must be exercised in judging how candid nurses can be about a practice that is illegal. ${ }^{2}$

Methodological comparisons of quantitative and qualitative studies were almost impossible: samples, terminology, questioning, vignettes, and interview techniques were all different. Moreover there were failures to address the complexity of the issues-for instance, in the Kuhse and Singer ${ }^{20}$ and Young et $a^{28}$ studies, which had been replicated and could be compared, the debate was too polarised. ${ }^{33}$

Another limitation was the lack of information about the validity and reliability of the measurement techniques used. Qualitative studies paid little attention to the trustworthiness of the data. The criterion that was used to evaluate the qualitative research was how accurately and reliably it could access the phenomena of interest (euthanasia) from the viewpoint of the participants (nurses). While all the qualitative studies did access the phenomena of euthanasia from the viewpoint of the nurses participating in the study, questions about the accuracy and reliability of the studies remained. Very few of the qualitative studies used any strategies to increase the worth of the qualitative data such as triangulation, peer debriefing or member checking. In spite of these limitations, the literature review does provide a number of valuable findings regarding nurses' attitudes toward euthanasia. Comments made by nurses in all the studies were generally exploratory in nature and showed that regarding euthanasia, nurses felt that there were issues that had not been addressed yet.

\section{Complementary research}

The myriad of data on nursing attitudes toward euthanasia in quantitative studies revealed widely differing percentages and gave an inconclusive picture, which did not reveal much about the reality behind nursing attitudes. The complexity of nursing attitudes cannot be captured in a polarised debate where attitudes are shown to be either simply for or against euthanasia. In this respect, McInerney and Seibold ${ }^{33}$ and van der Brug et $a l^{35}$ warn that the rigid structuring of many studies could prevent new insights in what is an area of nursing that has not been investigated in great depth. Verpoort et $\mathrm{al}^{3}$ reiterate this, noting that in many quantitative studies questions posed about euthanasia always used pro or contra terminology, leaving no room for a qualified response.

In this literature overview, we have noted that despite the fact that nurses often felt they could not put into words their ethical thinking, implicitly they were engaging in a complex reflective process with many principles, and factors involved. Further examination into the underlying principles that nurses cite in support of their attitudes, however, does not offer much more information. While nurses indicated such principles as, for example, "respect for autonomy" or "quality of life", as guiding their attitudes in favour of euthanasia, they also indicated that these ethical principles were too theoretical, and not true guides to the individual character of each patient's complex situation.

This raises questions about whether researchers are not imposing static, oversimplified ethical frameworks on nurses, which may not have a correlation to nurses' actual clinical experiences. Orpett Long ${ }^{39}$ describes how empirical research often allows people to select from "predetermined" sets of responses, giving them no opportunity to envisage any ambivalence about those choices. While bioethics all too often assumes a detached and disinterested reasonable person as undertaking choices in a logical manner, says Orpett Long, she notes that in real life the values held by people contain their "'felt" ideas and views on human experience. As such, people's values do not act as logical rules governing behaviour but are embedded in personal and cultural constructions of meaning. From this viewpoint people's choices on end of life decisions can be seen as being in conflict, ambivalent, and often with no satisfactory resolution. This review too illustrates that the ongoing interaction between theory and practice indicates that a more contextual, situated, and practice based ethical framework is needed to illuminate nurses' attitudes toward euthanasia.

The attitudes of nurses formed in clinical practice on such issues as palliative care, communication, emotions, decision making, and ethics should form the basis of further studies on ethical reflection as it appears in clinical practice. Empirical research (quantitative and qualitative) is necessary in order to undertake the identifying, listing and analysis of these ethical attitudes. Ethical research should in turn 
confront such data with the theoretical ethical concepts as they are developed in philosophical ethics. The results of the dialogue between empirical ethics and philosophical ethics contribute to ethical theory development through a better understanding of the way nurses reason and practice in situations where ethical dilemmas arise, as happens with euthanasia. Focus on the interplay between empirical (descriptive) and philosophical (normative) ethics may lead to a greater emphasis on how the two can work together, rather than stressing the differences between the two or valuing only philosophical ethics to the exclusion of empirical ethics. It is the dynamic interaction between both disciplines which contributes to a better empirical and theoretical understanding of ethical issues in practice and, consequently, to improved patient care. ${ }^{40}$

\section{Support in facing requests for euthanasia}

In their comments, nurses expressed great dissatisfaction with how they were expected to cope with issues around euthanasia, also saying that this dissatisfaction was compounded by their great needs in addressing the issues of palliative care; communication; emotions; decision making, and ethics. Due to their close relationship to patients and their families, nurses are vulnerable to being approached by the terminally ill requesting euthanasia. It is thus imperative that nurses understand the links between issues such as the limits of clinical practice, the problems of communication, and how to situate their emotions in the context of their ethical commitment to care in the best way possible for a dying patient. Nurses who are involved in caring for patients in the euthanasia process have warned that the caring commitment they are ethically required to give is of an all inclusive character, which demands much from them. It requires nurses to be technically as well as emotionally skilled. Such a caring commitment must include reflection on one's own values and emotions, which can be very difficult to confront. $^{35}$

Moreover, one area of important future developments that nurses have indicated is an issue in terms of both clinical practice and ethical guidance, concerns the relationship between euthanasia and palliative care. Nurses' positive attitudes toward palliative care, and their view that palliative care has to occur before euthanasia can be considered, together with their awareness of the need for greater education and research, indicate that the relationship between euthanasia and palliative care needs more exploration and discussion.

\section{Broadening the euthanasia debate}

These results can contribute to the societal and ethical debate about euthanasia, which until now has tended to be conducted solely from a medical perspective. Ethical reflection from a nursing perspective can serve to further orientate the developments of clinical practice guidelines and laws related to euthanasia, as well as call them into question. Nurses have indicated not only the justifications but also the difficulties and tensions that they have experienced in clinical practice with respect to euthanasia. The nursing perspective broadens the euthanasia debate by providing it with much needed critical insights about education in palliative care, communication skills, situating the emotions, decision making, and ethical guidelines. This can be of benefit not only to health care professionals, families, and patients directly involved in the euthanasia process, but also to all members of a society in their critical reflection on the issue of euthanasia. This indicates how important nurses' contributions toward the euthanasia debate are, and why further empirical research, as well as ethical reflection, is imperative and must not cease on this issue.

\section{Authors' affiliations}

M Berghs, C Gastmans, Faculty of Medicine, Centre for Biomedical Ethics and Law, Catholic University of Leuven, Leuven, Belgium

B Dierckx de Casterlé, Faculty of Medicine, Centre for Health Services and Nursing Research, Catholic University of Leuven, Leuven, Belgium

\section{REFERENCES}

1 Euthanasia Act 2002. Brussels: The Belgian Statute, 2002

2 Schwarz J. Assisted dying and nursing practice. J Nursing Scholarsh 1999;31:367-75.

3 Verpoort C, Gastmans C, De Bal N, et al. Nurses' attitudes to euthanasia: a review of the literature. Nurs Ethics 2004;11:349-65.

4 Van der Heide A, Deliens L, Faissat K, et al. End of life decision making in six European countries: descriptive study. Lancet 2003;361:345-50.

5 De Beer T, Gastmans C, Dierckx de Casterlé B. Involvement of nurses in euthanasia: a review of the literature. J Med Ethics 2004;30:494-8.

6 Shuman CR, Fournet GP, Zelhart PF, et al. Attitudes of registered nurses toward euthanasia. Death Stud 1992;16:1-15.

7 Anderson JG, Caddell DP. Attitudes of medical professionals toward euthanasia. Soc Sci Med 1993;37:105-14.

8 Davis AJ, Slater PV. US and Australian nurses' attitudes and beliefs about the good death. J Nurs Scholarsh 1989;21:34-9.

9 Takeo K, Satoh K, Minamisawa H, et al. Health workers' attitudes toward euthanasia in Japan. Int Nurs Rev 1991;38:45-8.

10 Asch DA, Shea JA, Jedrziewski MK, et al. The limits of suffering: critical care nurses' views of hospital care at the end of life. Soc Sci Med 1997;45:1661-8

11 Aranda S, O'Connor M. Euthanasia, nursing, and care of the dying: rethinking Kuhse and Singer. Aust Nurs J 1995;3:18-21.

12 Aranda S, Bence G, O'Connor M. Euthanasia: a perspective from Australia. Int J Palliat Nurs 1999;5:298-304.

13 Asai A, Ohnishi M, Nagata SK, et al. Doctors' and nurses' attitudes toward and experiences of voluntary euthanasia: survey of members of the Japanese Association of Palliative Medicine. J Med Ethics 2001;27:324-30.

14 Bittel N, Neuenschwander H, Stiefel F. "Euthanasia": a survey by the Swiss Association for Palliative Care. Support Care Cancer 2002;10:265-71.

15 Brown NK, Thompson DJ, Bulger RJ, et al. How do nurses feel about euthanasia and abortion? Am J Nurs 1971;71:1413-16.

16 Cartwright C, Steinberg M, Williams $G$, et al. Issues of death and dying: the perspective of critical care nurses. Aust Crit Care 1997; 10:81-7.

17 Fekete S, Osvath $P$, Jegesy A. Attitudes of Hungarian students and nurses to physician assisted suicide. J Med Ethics 2002;28:126.

18 Kitchener BA. Nurse characteristics and attitudes to active voluntary euthanasia: a survey in the Australian capital. J Adv Nurs 1998;28:70-6.

19 Kowalski SD. Nevada nurses' attitudes regarding physician assisted suicide. Clin Nurse Spec 1997;1 1:109-15.

20 Kuhse H, Singer P. Voluntary euthanasia and the nurse: an Australian survey. Int J Nurs Stud 1993;30:311-22.

21 Musgrave CF, Soudry I. An exploratory pilot study of nurse-midwives' attitudes toward active euthanasia and abortion. Int I Nurs Stud 2000;37:505-12.

22 Musgrave CF, Margalith I, Goldsmidt L. Israeli oncology and non-oncology nurses' attitudes toward physician assisted dying: a comparison study. Oncol Nurs Forum 2001;28:50-7.

23 Richardson DS. Oncology nurses' attitudes toward the legalisation of voluntary active euthanasia. Cancer Nurs 1994;17:348-54.

24 Ryynänen OP, Myllykangas $M$, Viren $M$, et al. Attitudes toward euthanasia among physicians, nurses, and the general public in Finland. Public Health 2002;116:322-31.

25 Stevens CA, Hassan R. Nurses and the management of death, dying, and euthanasia. Med Law 1994;13:541-54.

26 Tanida N, Asai A, Ohnishi $M$, et al. Voluntary active euthanasia and the nurse: a comparison of Japanese and Australian nurses. Nurs Ethics 2002;9:313-22.

27 Winget C, Kapp FT, Yeaworth RC. Attitudes toward euthanasia. J Med Ethics 1977;3:18-25.

28 Young A, Volker D, Rieger P, et al. Oncology nurses' attitudes regarding voluntary, physician assisted dying for competent, terminally ill patients. Oncol Nurs Forum 1993;20:445-51.

29 Ferrell B, Virani R, Grant M, et al. Beyond the Supreme Court decision: nursing perspectives on end of life care. Oncol Nurs Forum 2000;27:445-55.

30 Davis AJ, Davidson B, Hirschfield M, et al. An international perspective of active euthanasia: attitudes of nurses in seven countries. Int $J$ Nurs Stud 1993;30:301-10.

31 Kuupelomäki M. Attitudes of cancer patients, their family members, and health professionals toward active euthanasia. Eur J Cancer Care 2000;9:16-21.

32 Matzo M, Schwarz J. In their own words: oncology nurses respond to patient requests for assisted suicide and euthanasia. App Nurs Res 2001;14:64-71.

33 Mclnerney F, Seibold C. Nurses' definitions of and attitudes toward euthanasia. J Adv Nurs 1995;22:171-82.

34 Odgen R. AIDS, euthanasia, and nursing. Nurs Stand 1996;10:49-51.

35 Van der Brug YM, de Lange J, Philipsen H. Ervaringen van verpleegkundigen met euthanasie bii aids-patienten. Verpleegkunde 1996;11:143-55.

36 Verpoort C, Gastmans C, Dierckx de Casterlé B. The views of palliative care nurses on euthanasia: a qualitative study in Flanders, Belgium. J Adv Nurs 2004;47:592-600. 
37 Young MG, Ogden RD. The role of nurses in aids care regarding voluntary euthanasia and assisted suicide: a call for further dialogue. J Adv Nurs 2000;31:513-19.

38 The A-M. Vanavond om 8 uur...Verpleegkundige dilemmas bij euthanasie en andere beslissingen rond het levenseinde. Houten and Diegem: Bohn Stafleu Van Loghum, 1997. In Dutch.
39 Orpett Long $\mathbf{S}$. Life is more than a survey: understanding attitudes toward euthanasia in Japan. Theor Med 2002;23: 305-19.

40 Dierckx de Casterlé B, Grypdonck M, Cannaerts N, et al. Empirical ethics in action: lessons from two empirical studies in nursing ethics. Med Health Care Philo 2004;7:31-9.

\section{Clinical Evidence - Call for contributors}

Clinical Evidence is a regularly updated evidence-based journal available worldwide both as a paper version and on the internet. Clinical Evidence needs to recruit a number of new contributors. Contributors are healthcare professionals or epidemiologists with experience in evidence-based medicine and the ability to write in a concise and structured way.

Areas for which we are currently seeking authors:

- Child health: nocturnal enuresis

- Eye disorders: bacterial conjunctivitis

- Male health: prostate cancer (metastatic)

- Women's health: pre-menstrual syndrome; pyelonephritis in non-pregnant women

However, we are always looking for others, so do not let this list discourage you.

Being a contributor involves:

- Selecting from a validated, screened search (performed by in-house Information Specialists) epidemiologically sound studies for inclusion.

- Documenting your decisions about which studies to include on an inclusion and exclusion form, which we keep on file.

- Writing the text to a highly structured template (about 1500-3000 words), using evidence from the final studies chosen, within 8-10 weeks of receiving the literature search.

- Working with Clinical Evidence editors to ensure that the final text meets epidemiological and style standards.

- Updating the text every six months using any new, sound evidence that becomes available. The Clinical Evidence in-house team will conduct the searches for contributors; your task is simply to filter out high quality studies and incorporate them in the existing text.

- To expand the topic to include a new question about once every 12-18 months.

If you would like to become a contributor for Clinical Evidence or require more information about what this involves please send your contact details and a copy of your CV, clearly stating the clinical area you are interested in, to Klara Brunnhuber (kbrunnhuber@ bmigroup.com).

\section{Call for peer reviewers}

Clinical Evidence also needs to recruit a number of new peer reviewers specifically with an interest in the clinical areas stated above, and also others related to general practice. Peer reviewers are healthcare professionals or epidemiologists with experience in evidence-based medicine. As a peer reviewer you would be asked for your views on the clinical relevance, validity, and accessibility of specific topics within the journal, and their usefulness to the intended audience (international generalists and healthcare professionals, possibly with limited statistical knowledge). Topics are usually 1500-3000 words in length and we would ask you to review between 2-5 topics per year. The peer review process takes place throughout the year, and our turnaround time for each review is ideally 10-14 days.

If you are interested in becoming a peer reviewer for Clinical Evidence, please complete the peer review questionnaire at www.clinicalevidence.com or contact Klara Brunnhuber (kbrunnhuber@bmigroup.com). 